\title{
Haemodynamic monitoring in the coronary care unit using the Swan-Ganz right heart catheter
}

\author{
Harry G. Mond, ${ }^{1}$ David Hunt, and Graeme Sloman \\ From the Department of Cardiology, Royal Melbourne Hospital, Victoria, Australia
}

Thirteen patients with complicated acute myocardial infarction were studied in the coronary care unit to confirm the feasibility of using the Swan-Ganz right heart catheter to obtain pulmonary artery diastolic pressures, pulmonary arterial wedge pressures, and pulmonary artery blood samples for oxygen measurements. The aim of the study was to assess the haemodynamic changes after an acute myocardial infarction, the haemodynamic response to therapeutic interventions, and the diagnosis of a complicating ventricular septal defect.

Eight patients had left ventricular failure (group I) and five had cardiogenic shock (group 2). All patients in group I were studied within 24 hours of the onset of symptoms of acute myocardial infarction and the average pulmonary artery diastolic pressure on day I was $I 2 \mathrm{mmHg}$, falling to $6.5 \mathrm{mmHg}$ by day 3 (zero at manubriosternal junction). The pulmonary arterial wedge pressure showed a similar fall: $9 \mathrm{mmHg}$ on day I falling to $4 \mathrm{mmHg}$ on day 3. Only one patient showed a rise in pressures over the three days and he subsequently died in hospital. There was a good relation between the mean right atrial and the pulmonary arterial wedge pressures in the mild left ventricular failure patients $(r=0.86, P<0.001)$ but not in those with more severe failure $(r=0.53, P>0.05)$. At follow-up, one to three months after the infarction, all 7 patients studied had raised pulmonary artery diastolic and pulmonary arterial wedge pressures, both averaging I I $\mathrm{mmHg}$. All patients in group 2 with cardiogenic shock had raised pulmonary artery diastolic pressures, average 22 $\mathrm{mmHg}$, and pulmonary arterial wedge pressures, average $18 \mathrm{mmHg}$. There were no survivors in this group. Three case illustrations demonstrate the use of fluid loading, diagnosis of a ventricular septal defect, and haemodynamic monitoring in the treatment of cardiogenic shock.

The management of patients with acute myocardial infarction in coronary care units has in recent years resulted in a marked reduction in early mortality (MacMillan et al., 1967; Killip and Kimball, 1967; Sloman, Stannard, and Goble, 1968). This is attributed to continuous electrocardiographic monitoring with prevention and early treatment of life-threatening arrhythmias. Consequently the majority of deaths in the coronary care units today are not due to arrhythmias, but rather to the inability of the myocardium to sustain an adequate circulation, resulting in severe left ventricular failure and cardiogenic shock (Rutherford, McCann, and O'Donovan, I97I).

From clinical signs and the use of both invasive and non-invasive investigations, left ventricular dysfunction has been shown to be a common finding

Received II December 1972.

1 Research Assistant in receipt of a National Heart Foundation of Australia Grant-in-Aid. after an acute myocardial infarction (Karliner and Ross, 197I). Often the obvious clinical signs of cardiac decompensation are late in appearing and the early subtle signs are difficult to interpret, thus delaying rational timing of therapy. It has become increasingly apparent that a useful haemodynamic index of left ventricular function and consequently left ventricular failure is the left ventricular enddiastolic pressure (Karliner and Ross, I97I). Bedside catheterization of the left ventricle has been shown to be feasible but not without risk of complications (Diamond et al., I97I; Hamosh and Cohn, I971 ; Hunt et al., I970a). In the absence of mitral valve disease or pulmonary vascular disease, the pulmonary artery diastolic and the pulmonary arterial wedge mean pressures reflect the enddiastolic pressure of the left ventricle (Sapru, Taylor, and Donald, 1968; Schoenfeld et al., 1970; Kaltman et al., 1966; Balcon, Bennett, and Sowton, 1972; Forsberg, 1971). Thus both pressures can be used to assess and monitor the left ventricular filling 
pressure in patients after acute myocardial infarction.

Recently Swan et al. (1970) introduced a flowdirected balloon-tipped right heart catheter which allows simple bedside cardiac catheterization without the aid of an image intensifier. It is the purpose of this paper to report on our experience with this technique in the haemodynamic assessment of patients after acute myocardial infarction, especially the changes that occur after therapeutic intervention and in the diagnosis of a complicating ventricular septal defect.

\section{Subjects and methods}

Thirteen patients were studied, I I male and two female. The average age was 57, the youngest being 38 and the oldest 75. Right heart catheterization was performed in the coronary care unit at the Royal Melbourne Hospital, within 24 hours of the onset of myocardial infarction in II patients. Two patients with cardiogenic shock were studied more than 24 hours after the onset of symptoms of myocardial infarction. All patients studied had acute myocardial infarction based on W.H.O. criteria, class I (World Health Organization, 1971), and all cases were complicated by left ventricular failure or cardiogenic shock. Eight patients had an anterior myocardial infarction, 4 had inferior, and I had subendocardial infarction. Heart failure was treated with diuretics in Io and digoxin in II patients.

The 13 patients were divided into two groups.

I) Left ventricular failure This group comprised 8 patients with pulmonary crepitations not cleared by coughing, together with a ventricular gallop rhythm. It was further divided into two subgroups.

Mild left ventricular failure - basal crepitations only (5 patients).

Severe left ventricular failure - pulmonary crepitations involving at least half the lung fields (3 patients).

2) Cardiogenic shock ( 5 patients) The presence of a systolic blood pressure less than $90 \mathrm{mmHg}$, with evidence of reduced peripheral and central blood flow such as cold extremities, oliguria, and cerebral dysfunction.

The $5 \mathrm{~F}$ Swan-Ganz catheter (Edwards Laboratories) was used in all the studies. The catheter is so constructed that a small lumen, $1.7 \mathrm{~mm}$ in diameter, exists in its wall and parallels the major lumen. At its distal end the small lumen is connected to a latex balloon which can be inflated with $0.8 \mathrm{ml}$ of air. The inflated balloon directs the catheter from the right atrium into the pulmonary artery, and allows for rapid pulmonary 'wedging'.

Bedside cardiac catheterization was performed under sterile conditions using the right median cubital vein. The catheter was passed 40 to $50 \mathrm{~cm}$ along the vein, and the balloon inflated. 2500 units of heparin diluted to ro $\mathrm{ml}$ were then injected. If ventricular ectopic activity occurred, 50 to IOo mg lignocaine was given by intravenous injection. Using pressure monitoring and electrocardiographic control the catheter was then floated into the pulmonary artery and wedged. Pressure measure- ments were made using a Sanborn differential transducer Type $267 \mathrm{~A}$ with the zero level taken at the manubriosternal junction. The pressure signal was processed using a Hewlett Packard 350-1 100C carrier amplifier and the pressure curves obtained were permanently recorded on a Sample Electronics SE 3006 ultraviolet recorder using 'Oscilloscript D' Agfa-Gevaert print-out paper. High contrast recordings were obtained within a few minutes. All signals were observed on an EMI 4-channel slow scan oscilloscope throughout the procedure. Though a portable image intensifier was available, it was not required.

The upper limit of normal for pulmonary diastolic pressure was taken as $8 \mathrm{mmHg}$ and pulmonary artery wedge pressure as $7 \mathrm{mmHg}$ (zero at manubriosternal junction).

After the pressures were obtained the catheter was left in the pulmonary artery and the position checked daily by the use of a portable $x$-ray. Right atrial, pulmonary artery diastolic, and pulmonary arterial wedge pressures were obtained daily for three days or longer when the clinical condition remained poor. The catheter was kept patent by a slow infusion of 5 per cent glucose containing 5000 units of sodium heparin. Between studies the portion of the catheter lying outside the vein was covered in gauze soaked in alcoholic chlorhexidine.

A complication occasionally encountered with the use of the catheter was mild thrombophlebitis at the cutdown site. This was not prevented by the routine use of antibiotic powder. There were no local infections or unexplained fevers. Early in the series two patients had short episodes of ventricular tachycardia on the rapid withdrawal of the catheter through the right ventricle. The catheter was subsequently withdrawn slowly after completion of the study and this complication did not recur.

Blood $\mathrm{Po}_{2}$ measurements were made in the patients with cardiogenic shock, using the Beckman cuvette and physiological gas analyser (Model 160 ). The values were corrected for $\mathrm{pH}$ and converted to percentage saturation. The blood was collected without any air leak into heparinized glass syringes and placed in ice for transport.

Arterial pressure recordings were made in the 5 cardiogenic shock patients using a fine portex cannula 4 FG passed by the Seldinger technique into the femoral artery.

Informed consent was obtained from the patients for both the initial inpatient studies and the follow-up studies. The nature and purpose of the procedure was explained in detail. From one patient (Case I) consent was obtained from the relatives.

\section{Results}

The right atrial and pulmonary arterial wedge pressures in all the cases studied are illustrated in Fig. I. There is a correlation between these two pressures over the whole group $(r=0.64, n=35, P<0.01)$. If the mild left ventricular failure patients are considered separately then there is an excellent corre- 


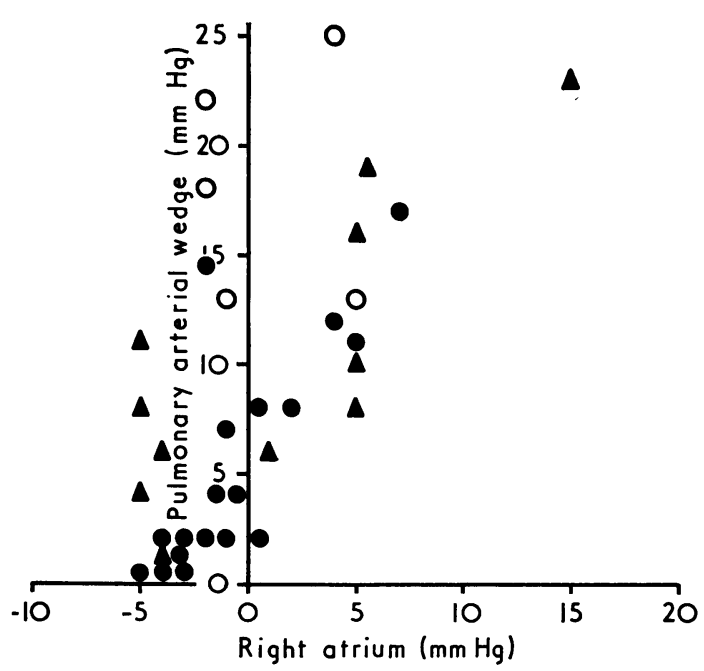

FIG. I Comparison of the mean pulmonary arterial wedge and the mean right atrial pressures, in all patients. In group $I$, the pressures were taken daily for three days and in group 2 only once. The closed circles represent the mild left ventricular failure patients, the closed triangles the severe left ventricular failure patients, and the open circles the cardiogenic shock patients. There is a good correlation between pulmonary arterial wedge and right atrial pressures with the mild left ventricular failure patients but not with the other two groups (see text).

lation between the right atrial and pulmonary arterial wedge pressures $(r=0.68, n=19, P<0.001)$. In the remaining patients with severe left ventricular failure and cardiogenic shock, however, there is a poor correlation between the right atrial and pulmonary artery wedge pressures $(r=0.53, n=16, P>0.05)$.

Group I: left ventricular failure The 8 patients in this group were studied daily for at least three days, the first study being within 24 hours of the onset of symptoms of acute myocardial infarction. There was one death in this group two weeks after infarction. The other 7 cases were studied one to three months after the infarction and I of these 7 patients died just before the six-month review.

The haemodynamic findings of all the patients in group I are listed in Table $I$. The average pulmonary artery diastolic and pulmonary artery wedge pressures of the whole group over the three days and in the follow-up period are listed with the mild and severe left ventricular failure subgroups in Table 2. The pressures were raised on admission especially in the severe left ventricular failure group and over the next two days they returned to within normal limits. At follow-up, the pressures were conspicuously raised, again maximal in the severe left ventricular failure group (Fig. 2 and 3 ).

Illustrative Case $A$ W.L. (Case I) a 38-year-old tramdriver was successfully resuscitated from ventricular fibrillation outside hospital, and an electrocardiogram showed an anterior myocardial infarction. After ad-

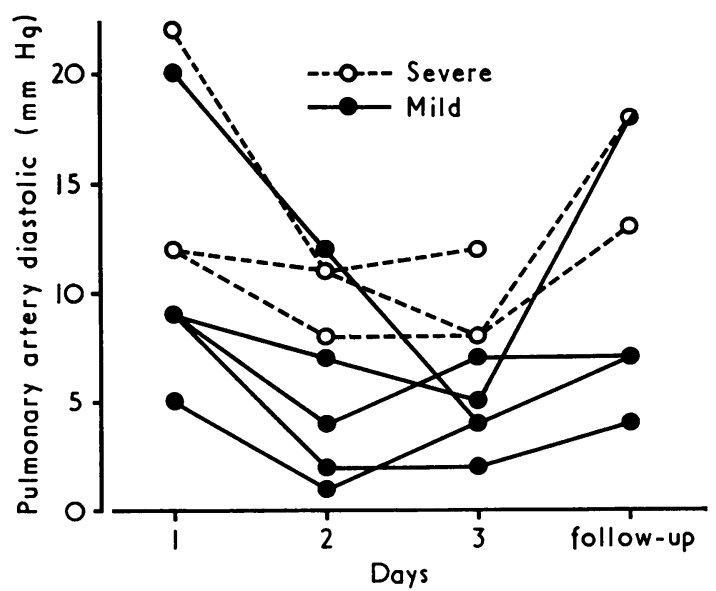

FIG.2 Pulmonary artery diastolic pressures in patients with mild and severe left ventricular failure after acute myocardial infarction. There is a fall in the pressure over three days and a rise in the follow-up period.

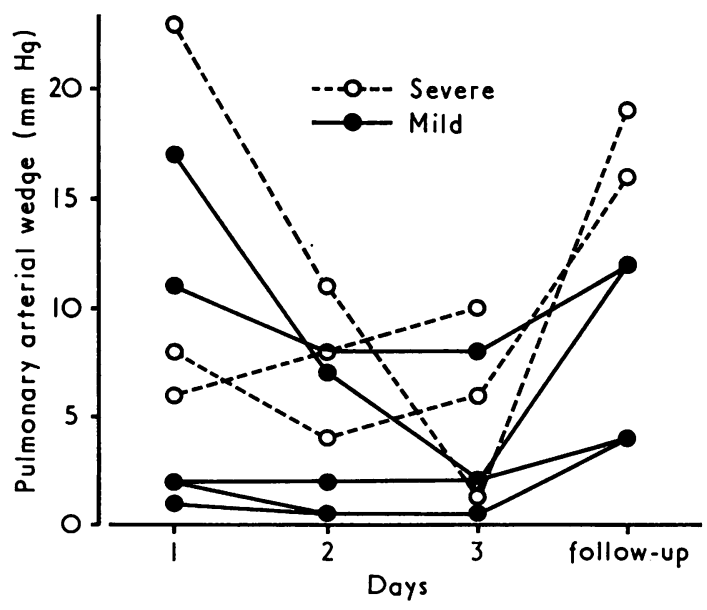

FIG. 3 Mean pulmonary arterial wedge pressures in patients with mild and severe left ventricular failure after acute myocardial infarction. There is a fall in the pressures over three days and a rise in the follow-up period. 
TABLE I Group I patients with left ventricular failure after acute myocardial infarction

\begin{tabular}{|c|c|c|c|c|c|c|c|c|c|c|c|}
\hline \multicolumn{3}{|c|}{$\begin{array}{l}\text { Case No., sex, } \\
\text { and age }\end{array}$} & \multirow[t]{2}{*}{ Infarct and severity } & \multicolumn{2}{|l|}{ Drugs } & \multicolumn{3}{|c|}{ Day I } & \multicolumn{3}{|c|}{ Day 2} \\
\hline & & & & $\begin{array}{l}\text { Coronary } \\
\text { care unit }\end{array}$ & Follow-up & $R A$ & $P A D$ & $P A W$ & $R A$ & $P A D$ & $P A W$ \\
\hline $\mathbf{I}$ & M & 38 & Anterior, severe & $\begin{array}{l}\text { Digoxin, } \\
\text { diuretics }\end{array}$ & $\begin{array}{l}\text { Digoxin, } \\
\text { diuretics }\end{array}$ & I5 & 22 & 23 & -5 & II & II \\
\hline 2 & $\mathbf{M}$ & 52 & Inferior, mild & $\begin{array}{l}\text { Digoxin, } \\
\text { diuretics }\end{array}$ & $\begin{array}{l}\text { Digoxin, } \\
\text { diuretics }\end{array}$ & 7 & 20 & 17 & $-\mathbf{I}$ & 12 & 7 \\
\hline 3 & $\mathrm{M}$ & 74 & Anterior, severe & $\begin{array}{l}\text { Digoxin, } \\
\text { diuretics }\end{array}$ & & I & 12 & 6 & 5 & II & 8 \\
\hline 4 & $\mathbf{M}$ & 54 & Inferior, severe & $\begin{array}{l}\text { Digoxin, } \\
\text { diuretics }\end{array}$ & $\begin{array}{l}\text { Digoxin, } \\
\text { diuretics }\end{array}$ & -5 & 12 & 8 & -5 & 8 & 4 \\
\hline 5 & $\mathrm{~F}$ & 45 & Inferior, mild & Digoxin & $\begin{array}{l}\text { Digoxin, } \\
\text { diuretics }\end{array}$ & 5 & 9 & II & $\circ$ & 7 & 8 \\
\hline 6 & $\mathbf{M}$ & 59 & Anterior, mild & Nil & Diuretics & -3 & 9 & 2 & -4 & 4 & 0 \\
\hline 7 & $\mathbf{M}$ & 45 & Anterior, mild & Nil & Nil & -3 & 9 & $\mathbf{I}$ & -4 & 2 & ○ \\
\hline 8 & $\mathbf{M}$ & 55 & Inferior, mild & $\begin{array}{l}\text { Digoxin, } \\
\text { diuretics }\end{array}$ & $\begin{array}{l}\text { Digoxin, } \\
\text { diuretics }\end{array}$ & 0 & 5 & 2 & -2 & $\mathbf{I}$ & 2 \\
\hline
\end{tabular}

RA, right atrial; PAD, pulmonary arterial diastolic; PAW, pulmonary arterial wedge.

mission to the coronary care unit soon after, his pulmonary arterial diastolic pressure was $22 \mathrm{mmHg}$ and pulmonary arterial wedge pressure was $23 \mathrm{mmHg}$. The clinical signs of severe heart failure responded rapidly to diuretic therapy and by the fourth day his pulmonary artery diastolic pressure had fallen to $5 \mathrm{mmHg}$ and his pulmonary artery wedge pressure to $2 \mathrm{mmHg}$. Despite his clinical improvement he remained deeply unconscious with poor peripheral circulation, but a systolic blood pressure between 90 and $100 \mathrm{mmHg}$. A negative fluid balance occurred with a high urine output due to the diuretic therapy. The serum urea rose to $65 \mathrm{mg} / 100 \mathrm{ml}$ (normal less than $30 \mathrm{mg} / 100 \mathrm{ml}$ ) with a normal serum creatinine. The blood volume (Volemetron-Ames) which was 5.01 . on admission had fallen to 4.01 . by day 4 . This dehydration state was managed by an infusion while monitoring the pulmonary artery diastolic and wedge pressures. Initially $500 \mathrm{ml} 5$ per cent dextrose in water was given rapidly. There was an immediate rise in both pressures to Io $\mathrm{mmHg}$, and after this satisfactory response an adequate intravenous fluid intake was maintained. Over 24 hours the patient's conscious state improved considerably and the urea fell to $28 \mathrm{mg} / \mathrm{r} 00 \mathrm{ml}$. He made a slow recovery, having sustained some permanent cerebral damage, and he was discharged home after five weeks.

This case illustrates over-enthusiastic diuretic therapy combined with inadvertent fluid restriction resulting in a low left ventricular filling pressure as reflected in the pulmonary artery diastolic and wedge pressures. A high peripheral vascular resistance was seen clinically by the poor peripheral circulation, and associated with this state was a rising blood urea and no improvement in the conscious state. The fluid load increased the left ventricular filling pressures without causing clinical pulmonary oedema and further intravenous fluid administration with monitoring of pressures resulted in continual clinical improvement.

Group 2: cardiogenic shock (Table 3) There were 5 patients with cardiogenic shock, 4 male and I female. Three of the patients were studied within 24 hours of the onset of symptoms. One patient was studied 3 days after the infarction and another at 36 hours. All 5 patients died in hospital. The pulmonary artery diastolic pressures were raised in all (range 14 to $27 \mathrm{mmHg}$ with an average of 22 $\mathrm{mmHg}$ ). The pulmonary arterial wedge pressures ranged from 13 to $25 \mathrm{mmHg}$, with an average of 18 $\mathrm{mmHg}$.

Illustrative Case B C.S. (Case 9), a 68-year-old baker, sustained an acute anterior myocardial infarction and was noted soon after to have a loud pansystolic bruit which had not been noted previously. His clinical condition deteriorated and he was transferred to the coronary care unit where on examination he was pale, short of breath, with a pulse of I IO and a blood pressure of $90 / 70$ mmHg. On praecordial palpation there was a paradoxical pulsation of the anterior myocardial wall and a systolic thrill. A fourth heart sound and a loud pansystolic bruit maximum at the left sternal edge were heard. Crepitations were audible half way up the lung fields but there was no evidence of right heart congestion.

The chest $x$-ray showed an enlarged heart, and a prominent vascular pattern suggestive of pulmonary congestion and/or pulmonary plethora. The diagnosis was anteroseptal infarction with anterior myocardial dyskinesia, and a ventricular septal defect. In view of the possibility of early operation a Swan-Ganz catheter was inserted. The pulmonary artery pressure was $56 / 14 \mathrm{mmHg}$ 


\begin{tabular}{|c|c|c|c|c|c|c|}
\hline \multicolumn{3}{|c|}{ Day 3} & \multicolumn{3}{|c|}{ Follow-up } & \multirow[b]{2}{*}{ Review } \\
\hline$R A$ & $P A D$ & $\overline{P A W}$ & $R A$ & $P A D$ & $P A W$ & \\
\hline-4 & 8 & $\mathbf{I}$ & 3 & 13 & 9 & Death 6 months \\
\hline$-\mathrm{I}$ & 4 & 2 & -2 & 7 & 12 & Alive 6 months \\
\hline 5 & 12 & 10 & & & & Death 2 weeks \\
\hline-4 & 8 & 6 & 5 & 18 & 16 & Alive 6 months \\
\hline 2 & 5 & 8 & 4 & 18 & 12 & Alive 6 months \\
\hline-3 & 7 & 0 & 2 & 7 & $\begin{array}{l}\text { Not } \\
\text { obtained }\end{array}$ & Alive 6 months \\
\hline $\begin{array}{l}-5 \\
-4\end{array}$ & $\begin{array}{l}2 \\
4\end{array}$ & $\begin{array}{l}0 \\
2\end{array}$ & $\begin{array}{l}-1 \\
-2\end{array}$ & $\begin{array}{l}4 \\
7\end{array}$ & $\begin{array}{l}4 \\
4\end{array}$ & $\begin{array}{l}\text { Alive } 6 \text { months } \\
\text { Alive } 6 \text { months }\end{array}$ \\
\hline
\end{tabular}

with a mean pulmonary arterial pressure of $13 \mathrm{mmHg}$. Blood oxygen analysis confirmed a left-to-right shunt at ventricular level, calculated at a pulmonary systemic flow ratio of 2.8 to 1 . Over the next two days the pulmonary artery diastolic and wedge pressures remained raised and the patient remained in pulmonary oedema despite the most aggressive treatment. It was agreed that the ventricular septal defect should be closed as an emergency procedure. However, while cardiac bypass surgery was being arranged the patient suffered a cardiac arrest and resuscitation was unsuccessful. Necropsy indicated a recent extensive anterior myocardial infarction which had also involved the ventricular septum, producing a septal defect near the apex. The mitral valve was normal and an old myocardial infarction at the apex had resulted in a small ventricular aneurysm. The bedside study enabled early confirmation of the diagnosis without inconvenience to the very ill patient.

Illustrative Case C F.J. (Case 12) a 75-year-old man was admitted with a 12-hour history of persistent severe retrosternal chest pain. The patient was dyspnoeic, cyanosed, pale, and sweaty. There was a poor volume pulse at a rate of $100 / \mathrm{min}$ and the blood pressure was $75 / 55 \mathrm{mmHg}$. The apex beat was impalpable, the heart sounds were soft, and no added sounds or bruits were heard. There was no right heart congestion evident, but bilateral crepitations could be heard over most of the lung fields. The electrocardiogram showed an extensive anterior myocardial infarction and the chest $x$-ray showed cardiomegaly with pulmonary venous congestion.

The patient remained hypotensive and in severe left heart failure. Bedside catheterization was performed to assess his haemodynamic state and to monitor drug therapy. The pulmonary artery pressure was 4I/20 $\mathrm{mmHg}$ and the pulmonary arterial wedge was $13 \mathrm{mmHg}$. The femoral arterial pressure was $75 / 45 \mathrm{mmHg}$. While monitoring these pressures, separate doses of intravenous isoprenaline $0.3 \mathrm{mg}$, norepinephrine $\mathrm{I} \mathrm{mg}$, and methyl prednisolone $2 \mathrm{~g}$ were given over three hours without any change in the pressures. At this point, 36 hours after admission, the serum aspartate aminotransferase was $\mathbf{8 2 0}$ units and the blood urea $156 \mathrm{mg} / 100 \mathrm{ml}$. Isoprenaline was continued but the patient's condition deteriorated and he died later that day. Necropsy showed total occlusion of the left main coronary artery and generalized disease of the right coronary artery. There was a recent extensive left ventricular myocardial infarction involving both anterior and inferior walls.

Although drugs did not affect the outcome in this patient, probably due to the extent of the infarction, this case does illustrate the potential value of haemodynamic monitoring during drug therapy in patients with cardiogenic shock.

\section{Discussion}

Without the aid of fluoroscopy, the Swan-Ganz catheter can be rapidly directed into the pulmonary artery in 95 per cent of cases and then wedged (Swan et al., 1970). Once the catheter lies in the right atrium, passage into the pulmonary artery under pressure monitoring usually occurs within a matter of seconds, and in the cases presented a wedge pressure was obtained in all but one instance.

TABLE 2 Summary of the average (mean) pulmonary artery diastolic and wedge pressures of patients in group I studied over three days and in the follow-up period. All patients in the groups are considered first and then the groups are subdivided into mild severe left ventricular failure

\begin{tabular}{|c|c|c|c|c|c|c|}
\hline \multirow[t]{2}{*}{ Group I } & \multicolumn{3}{|c|}{ Pulmonary artery diastolic pressure $(\mathrm{mmHg})$} & \multicolumn{3}{|c|}{ Pulmonary artery wedge pressure $(\mathrm{mmHg})$} \\
\hline & All patients & $\begin{array}{l}\text { Mild left } \\
\text { ventricular } \\
\text { failure }\end{array}$ & $\begin{array}{l}\text { Severe left } \\
\text { ventricular } \\
\text { failure }\end{array}$ & All patients & $\begin{array}{l}\text { Mild left } \\
\text { ventricular } \\
\text { failure }\end{array}$ & $\begin{array}{l}\text { Severe left } \\
\text { ventricular } \\
\text { failure }\end{array}$ \\
\hline Day I & 12 & IO & I5 & 9 & $6 \cdot 5$ & 12 \\
\hline $\begin{array}{l}\text { Day } 2 \\
\text { Day } 3 \\
\text { Follow-up }\end{array}$ & $\begin{array}{l}7 \\
6 \cdot 5 \\
10.5\end{array}$ & $\begin{array}{l}5 \\
4 \cdot 5 \\
8 \cdot 5\end{array}$ & $\begin{array}{l}10 \\
9 \\
15.5\end{array}$ & $\begin{array}{r}5 \\
4 \\
11\end{array}$ & $\begin{array}{l}3 \cdot 5 \\
2 \cdot 5 \\
8\end{array}$ & $\begin{array}{l}7 \cdot 5 \\
6 \\
18\end{array}$ \\
\hline
\end{tabular}


TABLE 3 Group 2 patients with cardiogenic shock after acute myocardial infarction

\begin{tabular}{|c|c|c|c|c|c|c|c|}
\hline \multicolumn{3}{|c|}{$\begin{array}{l}\text { Case No., sex, } \\
\text { and age }\end{array}$} & \multirow{2}{*}{$\begin{array}{l}\text { Infarct } \\
\text { Anterior }\end{array}$} & \multirow{2}{*}{$\begin{array}{c}\begin{array}{l}\text { Right } \\
\text { atrium }\end{array} \\
5\end{array}$} & \multirow{2}{*}{$\begin{array}{l}\begin{array}{l}\text { Pulmonary } \\
\text { artery diastolic }\end{array} \\
\mathbf{I} 4\end{array}$} & \multirow{2}{*}{$\begin{array}{l}\begin{array}{l}\text { Pulmonary } \\
\text { arterial wedge }\end{array} \\
\text { I3 }\end{array}$} & \multirow{2}{*}{$\begin{array}{l}\text { Comment } \\
\begin{array}{l}\text { Ventricular septal defect, death before } \\
\text { operation }\end{array}\end{array}$} \\
\hline 9 & $\mathbf{M}$ & 68 & & & & & \\
\hline IO & M & 68 & Subendocardial & -2 & 22 & 22 & Death in coronary care \\
\hline II & $\mathrm{F}$ & $5 \mathrm{I}$ & Anterior & 4 & 25 & 25 & Death in coronary care \\
\hline 12 & M & 75 & Anterior & $-\mathbf{I}$ & 20 & 13 & Death in coronary care \\
\hline 13 & M & 59 & Anterior & -2 & 27 & 18 & Death in coronary care \\
\hline
\end{tabular}

There were no complications apart from thrombophlebitis and infrequent arrhythmias when removing the catheter. No evidence of pulmonary thrombosis or infarction was seen in any of the patients though the catheter was left in the pulmonary artery for up to four days. The patients were carefully examined and the chest $x$-ray inspected daily in order to exclude wedging of the catheter. Others have reported complications which have included rupture of the balloon (Swan et al., 1970), pulmonary artery rupture (Chun and Ellestad, 1971), and intracardiac knotting (Lipp, O'Donoghue, and Resnekov, 197I) but these were not seen in our series.

This study confirms that there is a rise in the pulmonary artery diastolic and wedge pressures indicating raised left ventricular filling pressures after acute myocardial infarction. This rise in the filling pressure has also been recorded by other workers (Diamond et al., 197I; Gold, Leinbach, and Dunkman, 1971) even in the absence of clinical heart failure (Hunt et al., I970a).

Alterations in the left ventricular filling pressure have been shown to cause a rise in the pulmonary artery diastolic pressure (Schoenfeld et al., I970; Kaltman et al., 1966; Forsberg, 1971) and, as expected, in both the left atrial pressure and the pulmonary arterial wedge pressures (Forsberg, I97I; Sapru et al., 1968). On the other hand, Bouchard, Gault, and Ross (I97I) showed that in chronic myocardial disease, when the heart rate was raised in excess of 124 beats per minute, the pulmonary artery end-diastolic pressure might not reflect the left ventricular end-diastolic pressure. They reported that at these higher heart rates there might be an increase in the pulmonary artery end-diastolic pressure while the left ventricular end-diastolic pressure fell. These authors also showed that the left ventricular diastolic pressure, before atrial contraction, correlated more closely with the pulmonary artery end-diastolic pressure. This was also confirmed by Balcon et al. (1972) in patients with ischaemic heart disease. Hunt et al. (1970b) found that there was a parallel rise in the left ventricular and pulmonary artery end-diastolic pressures up to a left ventricular end-diastolic pressure of $20 \mathrm{mmHg}$ in acute myocardial infarction. Rutherford et al. (1971) found in their patients that the mean pulmonary artery pressure was a reliable objective measure of left ventricular dysfunction and hence a reliable index on which to base therapeutic manoeuvres. Therefore, though there are some limitations, we concluded that both the pulmonary artery diastolic and wedge pressures do provide a relatively easily accessible index of left ventricular function.

In many clinical situations, including acute myocardial infarction, a poor correlation has been shown between the right atrial and pulmonary arterial wedge pressures (Collins et al., 197I; Bell, Stubbs, and Pugh, 197I ; Forrester et al., I97I; Gold et al., 197I). Hence, in the management of patients with acute myocardial infarction, central venous or right atrial measurements may be seriously misleading (Ramo et al., 1970; Rapaport and Scheinman, 1969). In the cases presented there was good correlation between right atrial and pulmonary arterial wedge pressures, but only in the mild left ventricular failure cases. As the severity of the clinical left ventricular failure increased, the correlation deteriorated. In those severe cases, haemodynamic monitoring for evaluation of drug therapy was important and thus pulmonary arterial wedge pressure measurements become necessary.

The value of right heart catheterization and monitoring of pulmonary artery pressures in patients with acute myocardial infarction has been well established (Rutherford et al., I97I ; Schoenfeld et al., 1970; Hunt et al., 1970a; Rapaport and Scheinman, 1969; Fluck et al., 1967). Early diagnosis of heart failure before clinical signs become apparent, the differentiation of ventricular septal defect from papillary muscle dysfunction or rupture, and the management of cardiogenic shock are some of the clinical benefits. These diagnostic advantages far outweigh the very low morbidity from the procedure. With the introduction of the Swan-Ganz catheter, high quality pulmonary arterial wedge 
pressures can also be easily obtained. Forrester $\mathrm{et} \mathrm{al}$. (197I) have shown these pressures to be valuable in both the assessment of left ventricular failure and in monitoring fluid loads.

In the patients in group I (left ventricular failure), the pulmonary artery diastolic and wedge pressures which were raised on admission fell to normal levels by day 3 except in the one patient who subsequently died. This fall can be attributed to the natural history of the disease as well as to therapy with diuretics, digoxin, bed-rest, and occasional fluid restriction. In those patients who survived, the left ventricular filling pressures in the follow-up period were again raised. There had, however, been little alteration in the drug therapy to account for this (Table I). This rise in the filling pressures of the left ventricle found at the follow-up studies is similar to that reported in a comparable group of patients by Rahimtoola et al. (1971). In their patients there were normal or decreased cardiac and stroke indices. They concluded that this rise in the filling pressure resulted from alterations in the ventricular compliance, end-diastolic volume, or a combination of both these factors. Certainly a reduced compliance has been shown in both experimental animals and humans after acute myocardial infarction, even in the presence of normal enddiastolic volumes (Weisse et al., 1970; Smith et al., I97 I).

Case A illustrates the problem of assessment of the fluid status of a dehydrated patient who was subsequently given a fluid load under haemodynamic monitoring, resulting in a considerable improvement in his condition. The Frank-Starling function curve illustrates that an increase in the left ventricular filling pressures will normally result in an improvement in cardiac output provided that the pressure is below a peak of 20 to $24 \mathrm{mmHg}$ (Russell et al., 1970). The infusion of a rapid fluid load using low molecular weight dextran (Russell et al., 1970) or 5 per cent glucose (Coltart and Hamer, 197I) has been used to increase the left ventricular filling pressure. This technique provides both a means of assessing myocardial function and treating hypovolaemia whether it be due to overenthusiastic diuretic therapy, fluid restriction, or severe peripheral vasodilatation. By monitoring pulmonary artery diastolic and wedge pressures, the procedure can be performed without the risk of producing serious pulmonary venous congestion.

The 5 patients in group 2 in our series had cardiogenic shock and conspicuously raised pulmonary artery diastolic and wedge pressures, and despite most enthusiastic therapy all patients died in hospital. The first case illustrated in this group (Case B) developed a ventricular septal defect which was con- firmed using blood samples obtained through the Swan-Ganz catheter. Porter and associates (I97I) have illustrated the value of diagnosing a ventricular septal defect by bedside cardiac catheterization in a coronary care unit. They continued to monitor the pulmonary artery diastolic pressure as a guide to therapeutic manoeuvres and the patient later underwent successful cardiac operation.

Case illustration $\mathrm{C}$ was typical of the other cases in this group. Extensive myocardial infarction had resulted in cardiogenic shock. Monitoring of the pulmonary artery diastolic and wedge pressures and femoral artery pressures allowed drugs to be administered and the haemodynamic responses recorded. There was no significant response to isoprenaline, norepinephrine, or methyl prednisolone. The possible value of both isoprenaline and norepinephrine in the treatment of cardiogenic shock has been reviewed by Gunnar et al. (1970). They concluded that isoprenaline was unsatisfactory in the treatment of cardiogenic shock especially if profound hypotension was present. However, improvement in the mean arterial pressure, cardiac output, and systemic vascular resistance could be obtained in a majority of patients using norepinephrine.

It is concluded that in acute myocardial infarction, knowledge of the left ventricular filling pressure reflected by either the pulmonary artery diastolic or the pulmonary artery wedge pressures is of value for accurate evaluation of cardiac performance and subsequent therapeutic manoeuvres.

This study was supported in part by a National Heart Foundation of Australia Grant-in-Aid. The following companies lent their support to the project: Parke-Davis and Company, Philips Duphar Pty. Ltd., and Upjohn International Inc. Edwards Laboratories provided the Swan-Ganz catheters.

We thank technicians Miss Jayne Ramshaw, Miss Cecily Urquhart, SRN, and Miss Jillian McArdle, SRN, for their assistance.

We are grateful to the physicians of the Royal Melbourne Hospital who allowed us to study their patients.

\section{References}

Balcon, R., Bennett, E. D., and Sowton, G. E. (1972). Comparison of pulmonary artery diastolic and left ventricular end diastolic pressures in patients with ischaemic heart disease. Cardiovascular Research, 6, 172.

Bell, H., Stubbs, D., and Pugh, D. (I97I). Reliability of central venous pressure as an indicator of left atrial pressure. Chest, 59, 169.

Bouchard, R. J., Gault, J. H., and Ross, J., Jr. (197I). Evaluation of pulmonary arterial end-diastolic pressure as an estimate of left ventricular end-diastolic pressure in patients with normal and abnormal left ventricular performance. Circulation, 44, 1072. 
Chun, G. M. H., and Ellestad, M. H. (197I). Perforation of the pulmonary artery by a Swan-Ganz catheter. New England fournal of Medicine, 284, $104 \mathrm{I}$.

Collins, J. V., Clark, T. J. H., Evans, T. R., and Riaz, M. A. (I97I). Central venous pressure in acute myocardial infarction. Lancet, $\mathbf{x}, 373$.

Coltart, D. J., and Hamer, J. (1971). Response to rapid infusion or diuresis in acute cardiac infarction. British Heart fournal, 33, 72.

Diamond, G., Marcus, H., McHugh, T., Swan, H. J. C., and Forrester, J. (1971). Catheterization of left ventricle in acutely ill patients. British Heart fournal, 33, 489.

Fluck, D. C., Valentine, P. A., Treister, B., Higgs, B., Reid, D. N., Steiner, R. E., and Mounsey, J. P. D. (1967). Right heart pressures in acute myocardial infarction. British Heart fournal, 29, 748.

Forrester, J. S., Diamond, G., McHugh, T. J., and Swan, H. J. C. (197I). Filling pressures in the right and left sides of the heart in acute myocardial infarction. New England Fournal of Medicine, 285 , 190.

Forsberg, S. A. (I97I). Relations between pressure in pulmonary artery, left atrium, and left ventricle with special reference to events at end diastole. British Heart fournal, 33, 494.

Gold, H. K., Leinbach, R. C., and Dunkman, W. B. (I97I). Wedge pressure monitoring in myocardial infarction. New England fournal of Medicine, 285, 230.

Gunnar, R. M., Loeb, H. S., Pietras, R. J., and Tobin, J. R. (I970). The hemodynamic effects of myocardial infarction and results of therapy. Medical Clinics of North America, $54,235$.

Hamosh, P., and Cohn, J. N., (1971). Left ventricular function in acute myocardial infarction. Fournal of Clinical Investigation, 50, 523 .

Hunt, D., Potanin, C., Pombo, J., Russell, R. O., Jr., and Rackley, C. E. (I970a). Left ventricular function in clinically uncomplicated myocardial infarction (abstract). Clinical Research, 18, 313.

Hunt, D. U., Pombo Ramos, J. F., Potanin, C., Russell, R. O., Jr., and Rackley, C. E. (I970b). Intravascular monitoring in acute myocardial infarction (abstract). American fournal of Cardiology, 25, 104.

Kaltman, A. J., Herbert, W. H., Conroy, R. J., and Kossmann, C. E. (1966). The gradient in pressure across the pulmonary vascular bed during diastole. Circulation, 34, 377.

Karliner, J. S., and Ross, J., Jr. (1971). Left ventricular performance after acute myocardial infarction. Progress in Cardiovascular Diseases, 13, 374.

Killip, T., and Kimball, J. T. (1967). Treatment of myocardial infarction in a coronary care unit. American fournal of Cardiology, 20, 457.

Lipp, H., O'Donoghue, K., and Resnekov, L. (1971). Intracardiac knotting of a flow-directed balloon catheter. New England fournal of Medicine, 284, 220.

MacMillan, R. L., Brown, K. W. G., Peckham, G. B., Kahn, O., Hutchison, D. B., and Paton, M. (1967). Changing perspectives in coronary care. A five-year study. American fournal of Cardiology, 20, $45 \mathrm{r}$.

Porter, C. M., Karp, R. B., Russell, R. O., Jr., and Rackley, C. E. (1971). Pulmonary artery pressure monitoring in cardiogenic shock. Archives of Internal Medicine, 127, 304.

Rahimtoola, S. H., DiGilio, M. M., Sinno, M. Z., Loeb, H. S., Rosen, K. M., and Gunnar, R. M. (I97I). Cardiac performance three to eight weeks after acute myocardial infarction. Archives of Internal Medicine, 128, 220.

Ramo, B. W., Myers, N., Wallace, A. G., Starmer, F., Clark, D. O., and Whalen, R. E. (1970). Haemodynamic findings in 123 patients with acute myocardial infarction on admission. Circulation, 42, 567.

Rapaport, E., and Scheinman, M. (1969). Rationale and limitations of haemodynamic measurements in patients with acute myocardial infarction. Modern Concepts of Cardiovascular Disease, 38, 55.

Russell, R. O., Jr., Rackley, C. E., Pombo, J., Hunt, D., Potanin, C., and Dodge, H. T. (1970). Effects of increasing left ventricular filling pressure in patients with acute myocardial infarction. Fournal of Clinical Investigation, 49, 1539.

Rutherford, B. D., McCann, W. D., and O'Donovan, T. P. B. (1971). The value of monitoring pulmonary artery pressure for early detection of left ventricular failure following myocardial infarction. Circulation, 43, 655.

Sapru, R. P., Taylor, S. H., and Donald, K. W. (1968). Comparison of the pulmonary wedge pressure with the left ventricular end-diastolic pressure in man. Clinical Science, 34, 125 .

Schoenfeld, H., Fillmore, S., Scheidt, S., and Killip, T. (1970). Estimation of left ventricular diastolic pressure from pulmonary artery pressure in acute myocardial infarction (abstract). Circulation, 41 and 42, Suppl. 3, 59.

Sloman, G., Stannard, M., and Goble, A. J. (1968). Coronary care unit; a review of 300 patients monitored since 1963 . American Heart fournal, 75, 140.

Smith, McK., Russell, R. O., Feild, B. J., and Rackley, C. E. (197I). Left ventricular compliance in the year following myocardial infarction. Circulation, 43 and 44, Suppl. II, I23

Swan, H. J. C., Ganz, W., Forrester, J., Marcus, H., Diamond, G., and Chonette, D. (1970). Catheterization of the heart in man with use of a flow-directed balloon-tipped catheter. New England fournal of Medicine, $283,447$.

Weisse, A. B., Saffa, R. S., Levinson, G. E., Jacobson, W. W., Jr., and Regan, T. J. (1970). Left ventricular function during the early and late stages of scar formation following experimental myocardial infarction. American Heart fournal, 79, 370.

World Health Organization Report. Euro 8201 (5) (1971). Ischaemic Heart Disease Registers. Report of the 5th Working Group. World Health Organization, Copenhagen.

Requests for reprints to Dr. Graeme Sloman, Department of Cardiology, The Royal Melbourne Hospital, Gratton Street, Parkville, Victoria 3050, Australia. 